This synopsis is based on a part of a doctoral thesis entitled 'Physiology of forage maize (Zea mays L.) in relation to its production and quality', Agricultural University, Wageningen, 1983. ix +252 pp., 62 figs, 53 tables, 598 refs. English; English and Dutch summaries. The major part of this thesis has been published elsewhere.

Available as paper copy (order R009P, $f 40$ including postage) or on microfiche (order R009M, f 22.50 including postage) at: NARD, c/o Pudoc, P.O. Box 4, 6700 AA Wageningen, Netherlands (telex 45015 blhwg $\mathrm{nl}$ ).

\title{
A stochastic model for the simulation of management decisions in dairy herds, with special reference to reproductive performance
}

A. A. Dijkhuizen (Department of Farm Economics, Agricultural University, Hollandseweg 1, $6706 \mathrm{KN}$ Wageningen, Netherlands), Sj. Hibma ${ }^{1}$ (Zootechnical Institute, Veterinary Faculty, P.O. Box 80156, 3508 TD Utrecht, Netherlands) and J. A. Renkema (same address as the senior author)

Received 29 November 1984; accepted 1 February 1985

\begin{abstract}
A computer simulation model to study management decisons in dairy herds was developed. The first objective of the present model is to quantify the (economic) effects of different policies with respect to (re)productive failure and culling. The structure of the model also allows study of other aspects of management such as decisions regarding sire selection and feeding of the herd.

Key-words: simulation model, dairy cattle, economics, fertility, culling policy.
\end{abstract}

Introduction. Every farmer must frequently decide which cows should stay in the herd until further notice. To support him in making this decision, economic criteria for individual cows which differ in age, productive capacity and reproductive performance have been developed by using a replacement model in which the probabilities of disposal were taken into account in a deterministic way (Dijkhuizen et al., 1985). In the latter model, the critical production level below which it is not profitable to (re-)inseminate cows at different stages in each lactation was determined. It appeared to be desirable to gain further insight into the potential advantage of making replacement decisions over a number of years within different herds, based

\footnotetext{
${ }^{1}$ Present address: Nautical College 'Willem Barentsz', Dellewal 8, 8881 EG West-Terschelling, Netherlands.
} 
on the calculated optimum criteria instead of on other possible strategies. Real farm data to compare and evaluate these alternatives cannot be compiled. For this reason a dairy herd simulation model was developed, initiated by the work of Kuipers (1982). In the model practical conditions can be very closely imitated, because several events and effects of decisions are involved in a stochastic manner, i.e. according to certain probability distributions and leading to a spread in results at repeated calculations.

Model structure and contents. Each simulated herd consists of a fixed number of at most 100 cows (with additional youngstock), individually generated according to various predetermined herd characteristics (production level, reproductive status, herd life, breeding value of sires). Changes in the herd can be followed over 15 years, from one period of 20 days to another. The first 5 years are used to stabilize the initial situation; the next 10 years concern the experimental period in which the management alternatives are compared. Per alternative, the calculations are repeated 20 times to obtain statistically reliable results.

Of the components necessary to calculate the economic results per individual cow and per herd, milk receipts, reproduction (including sex and viability of calves) and involuntary disposal are involved in a stochastic manner. With regard to the (correlated) production of milk, fat and protein the model first determines standard curves, related to age of the cow and stage of lactation. Deviations are then simulated, based on normally distributed variation due to breeding value, permanent environment (both constant for a cow's lifetime), temporary environment (changing from one lactation to another), and short-term influences per 20-day period within each lactation (correlated during three successive periods). Within this framework the main coefficients are a heritability of 0.25 , a repeatability of 0.50 and a coefficient of variation of $15 \%$ for age-herd-year-season-corrected lactation production. Furthermore a total of 10 calving intervals are discernible, increasing at 20-day intervals from 340 to 520 days. The ultimate calving interval obtained is assumed to be dependent on the age of the cow, course of parturition and puerperium, stage of lactation, number of breedings, and efficiency of oestrus detection (with a Poisson-distributed interval until first observable oestrus), as well as on the farmer's policy with respect to (re-)inseminating and culling. Disposal of cows which does not result from prior decision making is referred to as involuntary. The probability of this disposal depends on age and stage of lactation, and is associated with some extra costs (e.g. reduced milk receipts and carcass value).

The other main factors in the model are feed intake, live body weight (including normal carcass value), and number of youngstock. Feed intake is calculated from requirements for maintenance, level of milk yield, percentage of fat in the milk and changes in live body weight. Moreover, capacity for dry matter intake, ratio between roughage and concentrates, and energy contents of feed stuffs have been taken into account. A change in live body weight depends on capacity for dry matter intake and requirements for milk yield and maintenance, and is thus interrelated with feed intake. To avoid the occurrence of unrealistic patterns, weight changes have been limited to a maximum ceiling. Lastly, the number of youngstock is re- 
Table 1. Provisional results of different policies with respect to (re-)inseminating and culling.

\begin{tabular}{llcc}
\hline & \multicolumn{3}{l}{ Maximum calving interval allowed (days) } \\
\cline { 2 - 4 } & 360 & $440^{1}$ & 520 \\
Average calving interval (days) & $-22^{*}$ & 373 & $+6^{*}$ \\
Empty cows culled (\% of the herd) & $+45^{*}$ & 9 & $-5^{*}$ \\
Average herd life (years) & $-3.1^{*}$ & 4.7 & $+0.8^{*}$ \\
Net return on labour per cow per year (Dfl.) & $-336^{*}$ & 1149 & +8 \\
\hline
\end{tabular}

${ }^{*} \mathrm{P}<0.005$.

1 The other alternatives have been expressed as a difference from this policy.

lated to the average herd life of the previous five years; females with the highest estimated milk receipts are retained. In case of short supply, late pregnant heifers can be bought. If the number of calving heifers is excessive, the model first determines if premature disposal of planned culls is possible; if not, the heifer concerned is sold.

Model behaviour. Based on normalized production patterns and price levels in 1981/1982, calculations to test the model's behaviour have been carried out. Some of the provisional results are presented in Table 1 , which shows a decrease in income if the maximum calving interval allowed decreases, in spite of the positive effect on the average calving interval of the herd.

Final remarks. After more precisely defined strategic breeding policies (taking into account the productive capacity of the cow) have been tested, the model will be extended by including different forms of mastitis. Furthermore a similar application of the model to sows in anticipated. Meanwhile the present model is being adapted for teaching veterinary and agricultural students.

\section{References}

Dijkhuizen, A. A., J. Stelwagen and J. A. Renkema, 1985. Economic aspects of reproductive failure in dairy cattle. I. Financial loss at farm level. Preventive Veterinary Medicine 3: 251-263; II. The decision to replace animals. Preventive Veterinary Medicine 3: 265-276 .

Kuipers, A., 1982. Development and economic comparison of selection criteria for cows and bulls with a dairy herd simulation model. Agricultural Research Reports 913. Pudoc, Wageningen .

This synopsis is based on a report entitled 'Een simulatiemodel voor de bestudering van het management t.a.v. produktie en gezondheid in melkveestapels' by Sj. Hibma. Zootechnical Institute, Veterinary Faculty, State University of Utrecht, Utrecht, Netherlands, 1983. iii +109 pp., 13 figs., 49 tables, 47 refs., appendices. Dutch.

Available as paper copy (order R029P, $f 30$ including postate) or on microfiche (order R029M, f 17.50 including postage) at: NARD, clo Pudoc, P.O. Box 4, 6700 AA Wageningen, Netherlands (telex 45015 blhwg $\mathrm{nl}$ ). 